\title{
Hydrogen from Sunlight Water Splitting: Is It Our Future?
}

\author{
Francisco Márquez $^{1}$, Kleber R. Pirota ${ }^{2}$, Carmen Morant ${ }^{3}$ \\ ${ }^{1}$ Nanomaterials Research Group, School of Science and Technology, University of Turabo, Gurabo, USA; ${ }^{2}$ Instituto de Fisíca Gleb \\ Wataghin, Universidade Estadual de Campinas, São Paulo, Brazil; ${ }^{3}$ Department of Applied Physics, Universidad Autónoma de Ma- \\ drid, Madrid, Spain. \\ Email: fmarquez@suagm.edu
}

Received September $7^{\text {th }}, 2013$; revised October $7^{\text {th }}, 2013$; accepted October $14^{\text {th }}, 2013$

Copyright (C 2013 Francisco Márquez et al. This is an open access article distributed under the Creative Commons Attribution License, which permits unrestricted use, distribution, and reproduction in any medium, provided the original work is properly cited.

\begin{abstract}
Environmental pollution and the growing need to find new sources of energy are some of the challenges of our century. The unstoppable growth of population, the increasing energy needs of emerging countries, and the foreseeable shortage of fossil fuels in a few years, make imperative to develop new energy generation processes and, in this regard, nanotechnology and the development of new nanomaterials will play a decisive role for the future of the planet.
\end{abstract}

Keywords: Hydrogen; Water Splitting

Hydrogen can be obtained from primary energy sources including coal, natural gas, biomass, wastes, so- lar, wind, hydro, geothermal or nuclear power. Hydrogen can be used in fuel cells or combustion engines with very high efficiency and no emissions of greenhouse gas and pollutants. If hydrogen is obtained from renewable energies, or conventional energy sources with capture of carbon, it would be possible to produce and use fuels on a global scale with nearly zero full fuel cycle emissions of greenhouse gas, reducing the emissions of pollutants. Nevertheless, and with the future perspectives in mind, the use of alternative methods to produce hydrogen is a must [1].

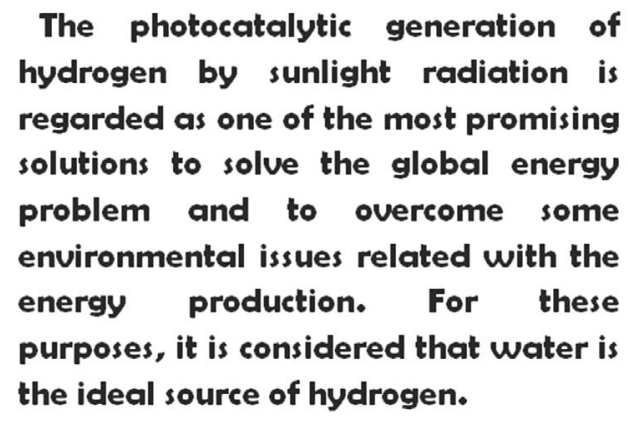

Biological hydrogen production has shown promise during the last decades. In fact, novel hydrogen production processes using solar energy and photosynthetic mi- croorganisms have been developed. However, photobiological production has limitations because it results in low yields compared to chemical processes [2].

The electrochemical production has proved to be one of the most convenient methods to produce hydrogen of high purity. However the major drawback is the energy required for this process, limiting this production to obtain exclusively very high purity hydrogen.

The photocatalytic generation of hydrogen by sunlight radiation [3] is regarded as one of the most promising solutions to solve the global energy problem and to overcome some environmental issues related with the energy production. For these purposes, it is considered that water is the ideal source of hydrogen.

Photocatalytic water splitting with generation of hydrogen is a green process that concerns activity of a semiconductor catalyst under sunlight irradiation and ambient pressure and temperature. Nevertheless most photocatalysts operate in a very limited way, by absorbing light in the ultraviolet range or near to that. Thermodynamically, the water splitting reaction is an uphill process characterized by a highly positive Gibbs free energy $\left(\Delta G^{\circ}=+238 \mathrm{~kJ} \cdot \mathrm{mol}^{-1}\right)$ :

$$
\mathrm{H}_{2} \mathrm{O}_{(l)} \rightarrow \mathrm{H}_{2(g)}+1 / 2 \mathrm{O}_{2(g)}\left(D G^{\circ}=+237.2 \mathrm{~kJ} \cdot \mathrm{mol}^{-1}\right)
$$

Since the seminal work of Honda and Fujishima [4] in 1972 on the water splitting using a single crystal of $\mathrm{TiO}_{2}$ 
as photoanode and Pt as cathode a vast body of literature describing this process has been published. More than one hundred different new catalysts including multicomponent oxides, sulfides or nitrides, have been synthesized for driving this reaction, and in all cases, has been demonstrated that the conversion efficiency is a function of a large number of factors, including how much the sunlight is absorbed, the energy of the absorbed photons, the efficiency of transforming absorbed photons in separated electrons and holes, how the carriers are moved through the material to the catalyst surface, and finally, how these separated electrons and holes are transferred to produce the desired products (hydrogen and oxygen). From a practical point of view, other relevant aspects to be considered include the stability and resistance under visible light irradiation, low toxicity, and the low cost of the synthesized materials.

To the best of our knowledge, the production of hydrogen from water splitting might be the only viable way to ensure our future though, of course, there is still much research to be done to transform these ideas into reality. Over the coming years, in which the energy needs will continue to grow exponentially, will be crucial to define the hydrogen (obtained from catalytic water splitting) as the only energy carrier capable of responding to our needs.

\section{REFERENCES}

[1] R. Chaubey, S. Sahu, O. O. James and S. Maity, “A Review on Development of Industrial Processes and Emerging Techniques for Production of Hydrogen from Renewable and Sustainable Sources,” Renewable and Sustainable Energy Reviews, Vol. 23, 2013, pp. 443-462. http://dx.doi.org/10.1016/j.rser.2013.02.019

[2] C. N. Dasgupta, J. J. Gilbert, P. Lindblad, T. Heidorn, S. A. Borgvang, K. Skjanes and D. Das, "Recent Trends on the Development of Photobiological Processes and Photobioreactors for the Improvement of Hydrogen Production,” International Journal of Hydrogen Energy, Vol. 35, No. 19, 2010, pp. 10218-10238. http://dx.doi.org/10.1016/j.ijhydene.2010.06.029

[3] V. Preethi and S. Kanmani, "Photocatalytic Hydrogen Production," Materials Science in Semiconductor Processing, Vol. 16, No. 3, 2013, pp. 561-575. http://dx.doi.org/10.1016/j.mssp.2013.02.001

[4] A. Fujishima and K. Honda, "Electrochemical Photolysis of Water at a Semiconductor Electrode,” Nature, Vol. 238, 1972, pp. 37-38. http://dx.doi.org/10.1038/238037a0 